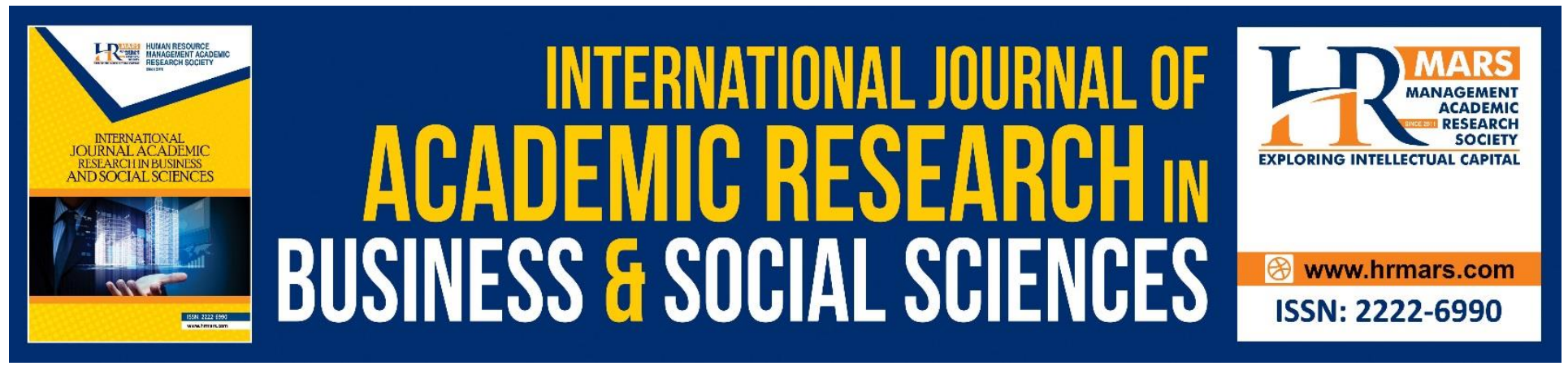

\title{
The Effectiveness of a Proposed Strategy Based on Video Stories on Youtube in the Development of Listening and Speaking Skills among the Non-Arabic Speakers
}

Nashaat Baioumy, Muhamad Zaid Ismail, Roslan Ab Rahman, Tasnim Mohd Annuar, Mohamad Zaidin Mohamad, Eman Ahmed Haridi

To Link this Article: http://dx.doi.org/10.6007/IJARBSS/v8-i10/4745 DOI: 10.6007/IJARBSS/v8-i10/4745

Received: 19 Sept 2018, Revised: 27 Oct 2018, Accepted: 28 Oct 2018

Published Online: 31 October 2018

In-Text Citation: (Baioumy et al., 2018)

To Cite this Article: Baioumy, N., Ismail, M. Z., Rahman, R. A., Annuar, T. M., Mohamad, M. Z., \& Haridi, E. A. (2018). The Effectiveness of a Proposed Strategy Based on Video Stories on Youtube in the Development of Listening and Speaking Skills among the Non-Arabic Speakers. International Journal of Academic Research in Business and Social Sciences, 8(10), 414-436.

Copyright: (c) 2018 The Author(s)

Published by Human Resource Management Academic Research Society (www.hrmars.com)

This article is published under the Creative Commons Attribution (CC BY 4.0) license. Anyone may reproduce, distribute, translate and create derivative works of this article (for both commercial and non-commercial purposes), subject to full attribution to the original publication and authors. The full terms of this license may be seen at: http://creativecommons.org/licences/by/4.0/legalcode

Vol. 8, No. 10, 2018, Pg. 414 - 436 


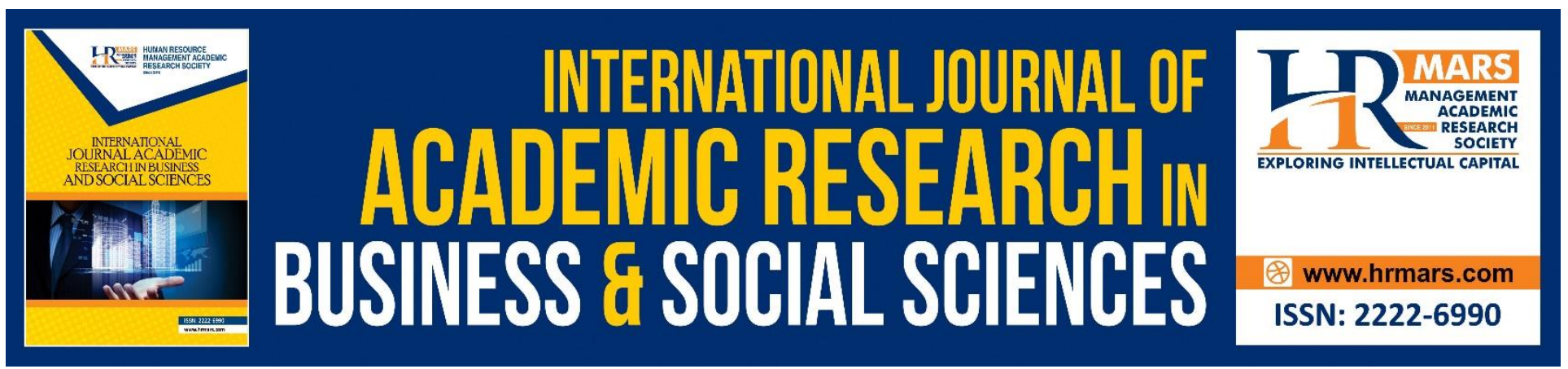

\title{
The Effectiveness of a Proposed Strategy Based on Video Stories on Youtube in the Development of Listening and Speaking Skills among the Non-Arabic Speakers
}

\author{
Nashaat Baioumy, Muhamad Zaid Ismail, Roslan Ab Rahman, \\ Tasnim Mohd Annuar \& Mohamad Zaidin Mohamad \\ Faculty of Islamic Contemporary Studies University of Sultan Zainal Abidin, Malaysia.
}

\section{Eman Ahmed Haridi}

Faculty of Post- Graduate studies for Education, Cairo University, Egypt.

\begin{abstract}
Many studies confirm the weakness of Arabic-speaking learners in acquiring general language skills and skills of listening and speaking in particular; where the development of listening skills and speech is one of the most important objectives of teaching Arabic to speakers of other languages; they represent the main tool of the learner to communicate with the native speakers in the Arabic language in different life situations to obtain his life needs, to express his thoughts and feelings, and to answer his intellectual and cultural questions. As well as intellectual communication Cultural and media sources, and cultural sources with original audio and visual sources in newsletters, reports and intellectual dialogues, watching entertainment and cultural films via the Internet and others. Therefore, the search for effective strategies in the development of listening and speech skills is a major demand and goal of many researches and studies on teaching Arabic to other speakers, which sought to build an educational strategy based on the selection of some video stories that meet the standard Arabic standards on the site of YouTube was selected two samples: experimental, and the control of the learners of the Arabic language Bam The results of the study revealed significant differences in favor of the experimental group, indicating the effectiveness of the proposed strategy in the teaching of Arabic to non-Arabic speakers. It also recommended that research be undertaken in building other strategies. Especially those based on the use of indigenous Arabic sources and their treatment within the framework of teaching standards for the development of language skills among non-Arabic speaking students at different levels of education.
\end{abstract}

Keywords: Strategy, Youtube, Listening Skills, Speech Skills, Non-Arabic Speakers 
INTERNATIONAL JOURNAL OF ACADEMIC RESEARCH IN BUSINESS AND SOCIAL SCIENCES

Vol. 8, No. 10, Oct. 2018, E-ISSN: 2222-6990 @ 2018 HRMARS

\section{The Theoretical Framework of Research}

Linguistic communication social process, the most important functions of human language, language is an individual tool to contact members of his group to achieve its objectives and needs, it is also a key factor so that the individual knows what is going on around him of events. The communication is an individual social process that starts with a set of ideas by a sender. The idea crystallizes in his mind, and then he looks for a way to convey it to a future, to inform it, to direct it, to change its direction, to develop its values or knowledge or other goals. This thesis affected by all the attendant stages of the variables.

Oral communication is an interactive binary process in which the sender and the receiver exchange roles. The sender may be in the future, and the future may be a sender. The oral language in the human communication process ranks first, precedes the written language in all areas of linguistic development (al-Naqa \& Hafez, 2002). The positions of oral communication are diverse in many areas of human activity. They are found in public places, the importance of oral communication with contemporary variables, the spread of democracy, the need to express opinions, and to listen to the opinions of others. To others through boards and various events, and therefore must pay attention to the development of listening and speaking skills.

There is increasing emphasis today on the importance of direct communication in the teaching of foreign languages, so the Listening skill has become the subject of great attention from researchers. Speech education has also become one of the most common objectives of foreign language education programs, because it is both a language and a social skill at the same time (Younis \& Raouf, 2003). Listening and speech are combined by sound; hence both are representing the vocal skills that an individual needs when communicating directly with others (Boungma, 2013). And listening to the linguistic property, it is the basis on which other language skills are built; it is the first human instrument that received the language at birth, as well as it was the first tool that transferred the human heritage from generation to generation, before the advent of writing; where listening and speech are the only means in the transfer and dissemination of heritage and knowledge. The listening is an inevitable input to writing for the acquisition of foreign language students, and the collection of different forms of knowledge and science. It is also an essential skill in the development of all language skills and cultural knowledge. It is the skill of other skills and the gateway to the development of speech, reading and writing. The actor acts of understanding, understanding, analysis, criticism and an expression of judgment over the audible. In the era of information technology, listening has increased; it has become the most widely used skill in tracking what is published through traditional and electronic sources of news, information and Explosive knowledge.

There were many views on the nature of listening, and the distinction between it and other linguistic terms such as "listening" and "listening", or where it is a skill that grows naturally, or needs the intended development processes that are subject to regulation, study and quantification, need to allocate specific times for their development, or automatically grow in combination with other language skills. 
The "hearing" is the reception of the vibrations of the sound from the source without interaction with it attention or thought, but "listening" is the intended attention to what the ear receives from the voices, and interact with them mentally and psychologically" (al-Mursi \& Khalaf, 2010), which is "receiving the voice and reaching the ear with intent and attention (hadi, 2003). It is a "mental process in which the listener gives special attention and deliberate attention to the ear from the voices" (Shehata, 1993). "Listening" is the deepest degree of listening, and it represents continuity in listening deeply and attentively" (Taa'ima, 2004).

Listening has great importance in life, in education, it is the first tool in language acquisition, which is our most used method of receiving the meanings and ideas around us, and the interaction with them, which is an effective skill all the time, even when it takes a person to sleep, hearing remains the sense that can be called through to return to attention and vigilance. Literary statistics have shown that "human beings have the following percentages: $11 \%$ for writing, $15 \%$ for reading, and $32 \%$ for $70 \%$ of their hours of vigilance in speech activity and $42 \%$ for listening" (Jabr, 1992). The daily use of listening more than any other skill; which emphasizes the importance of listening and shows his prominent role in the exchange of experiences and knowledge, and its primary role in the acquisition of language, whether native or foreign.

Hence the importance of training the foreign learner of the Arabic language to listen to the good; because of what this educational process of results on the future of the learner; all educational studies indicate the effective impact of training on listening ability of foreign students to acquire other language skills in speech, reading, and writing. As a result of the development of the languagecommunication tools, listening to the foreign language learner has become more familiar with the daily follow-up of news, information, knowledge and cultural products related to the foreign language of the learner, even after the learnkhaterer has returned to his or her home country, in it.

The teaching of listening to non-Arabic speakers requires focusing on cognitive, experiential, and psychological aspects (al-Mursi, \& Khalaf, 2010).

And these aspects:

1. Behavioral side: It is about sitting, focusing attention, taking appropriate conditions for good listening, keeping silent, and not interrupting or distracting the speaker.

2. The appropriate listening content: This is provided to the students in different teaching methods, and the adoption of some techniques through cassette tapes, recordings, flyers and videos.

3. Cognitive aspect: It includes enhancing the skills of auditory memory, auditory comprehension, audio discrimination, and audio visualization.

The acquisition of listening skills aims to be able to understand the native speakers of the language in real life situations and non-educational communication; because educational attitudes are made positions, rely on the issuance of speech.

These are carefully chosen to suit the learner at a certain level, as well as deliberate needs. These disciplined educational procedures are not found by the foreign listener in natural conversation in any real area of conversation or through a means of communication. In addition to this, intensive 
audio and intensive training is required to equip non-Arabic speakers with listening language skills, as well as to train quickly in the comprehension of audio through original language models and materials in Arabic. Where he cannot ask the speaker to slow down, repeat, or explain what he meant.

There are special criteria that must be available in the selection of the text / material for listening to students who speak non-Arabic, the most important:

(Khater., 1989 \& Ghazaleh, 2002).

1. Clarity: that the language of the text / article is a living language used, clear, and far from obscene, indecisive, or prolonged complex, or a blunt abbreviation that prevents comprehension and hinders understanding.

2. Appropriation/ suitability: The text / article shall be appropriate for the linguistic level of international students, and appropriate for their purposes, and their social and cultural characteristics.

3. Objectives: The text / material should aim to acquire a specific set of skills, new vocabulary, and language knowledge and cultural requirements for students at this level.

Many studies have pointed to the lack of foreign studies and the scarcity of Arab studies that are deeply concerned with listening skills, in comparison to the number of studies conducted in other language skills, including the study of "Rowen", in 1938, and the study of "Bour" in 1986, the subskills of listening skills were identified: the ability to set ideas, identify listening, discover relationships, retrieve information and data, derive judgments, understand key word meanings, and provide evidence and evidence. Among the Arab studies examined in this study are Taaima (2004) and Boungma (2013).

The words spoken by the speaker voices expressing what in his mind, and touring the same feelings and emotions, and the demand of needs, and what is rich in his mind of opinion or thought, and what he wants to provide him with other information or so in fluency and flow with its validity in expression and its integrity in performance. Speech can also be defined as the ability to use language to convey ideas and feelings, and to achieve various communicative purposes. It includes the ability to think and use different signals in the clarification of meaning (al-Mursi \& Khalaf, 2010).

Speech is one of the most important colors of activity in the linguistic production of adults and young people alike. People use speech more than the reference or writing in their lives, which is the main form of linguistic communication for man. Thus, speech is the most important part of language practice and its uses (Madkour, 1991). Skill is the skill most needed for a native foreign speaker, speech skill involves complex processes to build meanings and words, requiring the speaker to make decisions about: why Communicates? How does it continue? And who communicates with? When does it last? Depending on the diversity of needs and the different contexts, within the cultural and social dimension of the subject of dialogue, and in addition, it involves a dynamic and reciprocal relationship between the speaker and the listener, resulting in interaction, manufacturing and modification of the discourse within a narrow and limited time frame. 
In the functional analysis of the words, the lowest interaction is characterized by traditional routines, i.e. it focuses on information or interaction (Description, comparison, justification, prediction, decision), focus on personal information, and language functions in so-called meaning negotiation and interaction management (Brown, 1987).

"The skill of speech is a complex skill; it requires an integrated mental activity, and learning this skill does not happen between day and night, nor on the eve of its omission. It is a process that takes time and requires the patience, effort and wisdom what the teacher should have (Taaima, 1986). The foreign student, when he is strong, accepts the study of the Arabic language, but it is with strong conviction that the language means speech, so we find him eager and eager to use the new language in communicating with those around him. The people of the language, or those around him who use his language; The modern methods of teaching foreign languages to develop the skill of speech; they enable the student to achieve a quick connection in the daily life situations, and also enables him to spend his purposes and fill his needs with the use of his new educated language.

The teaching of speech in foreign language is important in several ways (Ibrahim, 1966):

1- It is the most important goal of studying languages, because it is the means of communication, understanding and first understanding.

2- The inability to speak has a significant impact on the failure of students to communicate directly and the repetition of failure resulting from the disorder and loss of self-confidence and vice versa, the successful communication of foreign students' native speakers in the educated language is strongly pushing for more of learning.

3- Lack of confidence and fluency in speech resulting in the lack of opportunities, and the loss of interest in the effort to learn foreign language.

\section{Teaching Speech should take into Account Two Processes}

Initial: Provide a diverse content of the speech that helps the student to communicate and express himself and his needs, and ideas, and feelings, its culture, its surroundings, etc. The second process is its training in the development and use of this content in other situations.

Therefore, the objectives of teaching speech to non-Arabic speakers should be as follows (Bakr \& Hachem, 1984):

1. Provide them with the appropriate vocabulary and structures in different communication situations.

2. Develop their ability to use appropriate expressions and correct language in light of the diversity of communication positions.

3. Develop their ability to understand the formulas of questions and ways to answer them.

4. Develop their ability to speak in a variety of short sentences in one subject or different topics.

5. Develop their ability to develop and use the linguistic crop that grows over time with an understanding of meaning.

6. Preparing them for vital situations that require fluency and accuracy in speech by expanding the areas of speech. 
INTERNATIONAL JOURNAL OF ACADEMIC RESEARCH IN BUSINESS AND SOCIAL SCIENCES

Vol. 8, No. 10, Oct. 2018, E-ISSN: 2222-6990 C 2018 HRMARS

7. Enabling them to express their ideas or what they see in words sound within the limits of what has been learned.

8. Enabling them to speak in all the colors of linguistic activity required by society in the affairs of life and knowledge.

In speech development processes, emphasis should be placed on important and complementary aspects:

\section{Voice Side:}

In which the speaker focuses on the correct pronunciation and output of the characters from the correct exits, and diversify the tone of voice with different methods, such as wonder and question and wish and ... etc. And stop the sound in the correct positions.

\section{Language Side:}

The focus is on choosing the right words, expressing ideas with useful sentences, using sentences and proper structures, and using examples to explain, detail, and link phrases with appropriate tools.

\section{Intellectual Side:}

It is the thinking of the speaker in what he or she will speak about. In this aspect, he is interested in identifying, selecting and arranging ideas, supporting them with evidence and evidence, and determining their clarity, diversity, interdependence and communication with the subject.

\section{The Concrete Side:}

In which the speaker focuses on the consideration of others, and the use of concrete expressions of movements of the face, body, head, gestures and signals; to express the meaning and embodiment and increase the power of influence in the listener.

\section{Interactive Declamation Side:}

In which the focus will be on the respect and enjoyment of listeners, and their exclusion to participate in the conversation. And be careful to enjoy trust and sense of humor.

There is a set of important directions for the teacher to follow when developing the speech of his foreign students, namely:

1. Teaching speech means practicing speech. 2. Students should express real experience. 3. Training to draw attention. 4. Not opposition and frequent correction. 5. Do not exceed the teacher in the level of expectations of the performance of students to speak. (Taima, 1986).

Several studies have identified the subtraction skills of speech skills. These studies include Taaima (2004), al-Anati (2009) and Salem (2015).

While integration in the teaching of language skills is important, integration in teaching listening and speaking skills is imperative, listen is a willingness to speak, and speech - in most cases is a reaction caused by stimuli and perceptions of operations listening to and listening to sounds, 
understanding vocabulary, analyzing and interacting with words and structures, by adding some special concepts and ideas, in order to reach the main and secondary passages of the message the sender intends on a topic and then begin to speak, And it is the audio version embodied in the output of the previous listening processes to express the content of the listening by highlighting the feelings and thoughts, and what the individual wants to convey information and ideas to others in a way that suits the communication situation (Khatib, 2008).

Thira What skill Receptive turns in listening to the productivity of the skill to speak, and also requires the processing of speech and composition of attention and wait for a review or follow-up or thinking about listening, which is based upon speech production again. And the stories of the best topics, and most effective in the development of complementary skills of listening and speech, and the features of the story in the teaching of Arabic to many foreigners, including:

1. Vocabulary and linguistic structures in the story represent common vocabulary and syntax in life for linguistic communication in a foreign language.

2. The linguistic methods in the story embody the real strategies used by the characters in communication, understanding and linguistic expression, and linguistic, psychological and social characteristics.

3. Culture in the story reflects the culture of speakers of the language or represents a mixture of global cultures that express the interests of foreign speakers and reflect their values and intellectual attitudes.

4. Story building including the subject, events, characters, nodes, etc., etc. represents a conceptual framework helps foreign students understand the voice, and helps them start talking about it: calling, explaining, interpreting, and criticizing.

5. The subject of the story, and events and language appropriate to the characteristics of scholars, attract students, and longing, and push them to integrate in learning the language, and the acquisition of vocabulary and structures and methods, away from boredom and monotony, and mental exhaustion in learning.

6. Memory retention story events long, and easy to retrieve, and thus help in the survival of the longer impact of learning, and the acquisition of the continuous vocabulary and linguistic structures learned from the story.

7. The story of its events and personalities fertile field for the integrated development of different language skills and facilitate their acquisition quickly and efficiently compared to other texts and language materials.

There are criteria for choosing the story in the programs of teaching Arabic to non-speakers (alAnati, 2009)., namely:

1. To choose at the beginning of the stories easy to language, and is linguistically easy to rely on the vocabulary and methods used language and representation or approaching the real language and non-dumping in literature. 
2. The story is short and easy to constructively in the simplicity of events, the ease of node, and relies on direct narration and the lack of technical techniques used stories.

3. To choose from the stories close to the cultural background and psychological characteristics of social students.

4. To be directed to the learners of Arabic in general speaking and non - native speakers and not directed to specialists in Arabic literature.

5. To target the development of language competence, and communication efficiency, and not to exceed the specialized literary competence.

6. The theme of the story should be a general human subject that is not exclusively concerned with the Arab-Islamic culture but is presented in all other cultures and civilizations.

7. Free of the story of the political trends and complex ideology.

The use of stories in the development of listening and speech skills can be done with the following pictures:
a. The expression of storytelling.
b. Supplement the missing stories.
c. The extension of short stories.
d. To narrate, discuss, summarize and represent stories that are read or heard.

The presentation of the story should also be followed by a discussion on some questions, such as: What is the subject of the story? and what characters and the main events? What information, qualities and roles related to these personalities and events? And I enjoy the part in this story? What is the best personality? and why? What meanings do you understand from this story? What other appropriate titles? How do you feel about the contents and characters of the story and its events? What is your own experience? What are the cultural aspects (Arab, Islamic, and global) that characterize the story? Students should also be provided with language training to consolidate the acquisition of vocabulary, compositions, and linguistic methods, such as: What is the meaning? What is single...? What is the plural...? What is the actor..? What is the object..? What is the linguistic root of...? ...etc.

The teacher and students must prepare before the story is read. This willingness includes preparing a strategy for presenting the story, choosing the way in which it is presented, how they interact with it, their assignments at each stage of the presentation and ensuring proper organization of the actions in light of the goals and target language skills.

There should also be criteria for returning students to tell and evaluate the story. One of the most important of these criteria is to ensure knowledge that the story is good, the integrity of the sentences, the expressions and the details, the use of the words represented for the meaning, the pronunciation of the words well, the lack of emphasis on the use of a letter of carriage, or a letter of sympathy, or only one link of language links, as well as critical discussions and postmodern after the story, Ensure that they understand them well and gain their meaning and their methods. 
The Internet and social networking sites have become an important repository for the original and audiovisual materials of foreign languages, especially the languages of the world, including the Arabic language, which occupies an important place for those who want to, learn from other languages. The audio and visual inventory of the Arabic language is varied on the web in recordings Audio-visual, newsletters, programs, seminars, and documentary, representational and historical videos. It represents the real historical, social, cultural and political issues of the Arab societies. It also contains a great original diversity of the Arabic vocabulary, methods, and structures common to Contemporary Arab speech.

For this reason, the teaching content of the current research has been based on some of the selected stories of the classical language, suitable for learners, on YouTube, as it is the most important site for foreign students to engage in observations and to learn about topics and events in Arabic.

\section{RESEARCH PROBLEM}

Many studies have proven the weakness of Arabic-speaking learners in listening and speaking skills, as recommended looking for methods and strategies that will help develop those skills among learners at different levels and their characteristics (Saleh, 2005. al-Khatib, 2008; Boungma, 2013). Through the researcher's experience in working in Arabic language departments, and access to curricula for non-Arabic speakers in many universities and educational centers in Egypt, Kazakhstan, Russia, Malaysia and Indonesia, and others, the researcher found that it focuses on the teaching of students language materials from grammar, And the teaching of literary materials that study the literary ages, rhetoric and criticism, while neglecting these approaches attention to language skills in general, and listening and speech skills in particular; which led to the weakness of learners in effective communication with the means of audio and visual communication of the Arabic language As well as the weakness of their skills in oral communication with speaking it from its origin; to know information or conduct dialogues, social, cultural or scientific discussions; and this is determined by the problem of the current search in the following questions:

1. What integrated listening and speech skills in learning the story, appropriate for learners of Arabic-speaking to other present research sample?

2. What is the proposed strategy based on the content of the selected stories on YouTube to develop these Integrated Skills for Students Current Research Sample?

3. What is the appropriate tool to measure the skills of listening and speech integrated in the story of the students of the current research sample?

4. What is the effectiveness of the proposed strategy in developing these skills among the students in the current research sample?

\section{RESEARCH OBJECTIVES}

1. Building an integrated list of listening skills and speech in the story, and suitable for learners of Arabic speakers of other languages students sample current research.

2. Building a proposed strategy to teach the collection of selected stories on YouTube website to develop these skills for students in the current research sample. 
3. Building an appropriate tool to measure the skills of listening and integrated speech in the story of the students in the current research sample.

4. Knowing the effectiveness of the proposed strategy in the development of these skills of students in the current research sample.

\section{RESEARCH IMPORTANCE}

The current research is expected to benefit specialists and teachers in the field of teaching Arabic to non-Arabic speakers through:

1. Utilizing the list of listening skills and integrated speech in the story, in the preparation of programs, and the implementation of lessons for their students in different contents and levels.

2. Utilizing the tool to measure the skills of listening and integrated speech in the story.

3. Utilizing the proposed strategy in teaching selected stories on YouTube to develop these skills for their students at different levels of education.

4. To benefit from the theoretical framework, experimental construction of the current research in the preparation of research, or to deepen understanding on some issues of teaching Arabic to other speakers.

\section{SEARCH TERMS AND IDIOMS}

\section{Proposed Strategy}

The strategy is "an integrated set of planned actions that stem from specific conceptual framework in order to achieve a set of objectives" (El-Laboudi, 2003). The strategy proposed in the current research is a plan that includes instructions, procedures, and disciplined applications to teach the story to non-Arabic speaking students in order to develop an integrated development of their listening and speaking skills, to verify their understanding of the elements of the story and to understand their linguistic, educational, intellectual and cultural contents Effective discussions around her, and her applications and criticism.

\section{Integrated listening and speech skills in story learning}

Skill is the "thing that an individual learns and performs easily and accurately whether it is physical or mental" (Saleh, 1996). A complex activity that requires a period of intentional training, organized practice and experience, This activity usually has a useful function, and the point of judgment is speed and accuracy (Hatab \& Sadek, 1996).

The skills of listening and speaking are integrated into story learning in the current research: those performances and applications, and integrated speech, in learning the story for students who speak non-Arabic, and the function to enable them to understand the elements of the story, and Linguistic, educational, cultural, intellectual understanding and comprehension and the ability to conduct effective discussions around it, and on their applications and criticism. 
INTERNATIONAL JOURNAL OF ACADEMIC RESEARCH IN BUSINESS AND SOCIAL SCIENCES

Vol. 8, No. 10, Oct. 2018, E-ISSN: 2222-6990 C 2018 HRMARS

\section{RESEARCH INSTRUMENTS (TOOLS)}

1. A list of the integrated listening and speaking skills in learning the story:

The list has been prepared in light of the following steps:

a. The study of literature and research related to the identification of appropriate listening and speaking skills for Arab students in general, and for Arabic learners who speak in particular.

b. Preparation of a preliminary list of skills and presentation to a group of arbitrators of experts and specialists (10 arbitrators) in the teaching of Arabic to non-Arabic speakers; to ascertain their veracity and suitability;

c. Making the necessary adjustments in the light of the views and proposals of the arbitrators.

d. Preparing the list in its final form; it included (23) an integrated skill in listening and speaking in the story, that are (3) to suggest other titles suitable for the educational content of the story (4) to remember the main and secondary events in the story; (5) to clarify the role of the events in the development of the story; The story and its end, (6) identifying the main characters in the story and information about them, (7) judging the main characters in the story through their physical, mental or mental behaviors or traits; (8) narrating the roles of the main characters in the story; (9) re- narrating the story, (10) summarize the story, (11) distinguish between the real expressions and metaphorical expressions in the story, (12) explain the meaning of the taboo (13) to relate the story to personal experiences and selfvalues; (14) to infer social, cultural or historical characteristics through the story; (15) to relate the story to Arab, Islamic, or global cultural characteristics; The story in short sentences, (17) the representation of some of the events of the story, (18) the distinction between the linguistic methods used in the story, (19) the output of the characters from the correct exits, (20) the use of vocabulary appropriate to the intended meaning, (22) consider the proportionality between the components of the sentence in recalling, femininity and number, (23) diversify the use of appropriate linkage tools among sentences.

\section{Card to measure the skills of listening and speech integrated in the story of the students Study Sample}

The card has been prepared in the light of the following steps:

a. Determine the goal of the card: Measure the extent to which the students acquired the research sample of the listening skills and integrated speech in the story before and after the research experience.

b. Dimensions of the card: The vocabulary of the card was prepared to measure the listening and speech skills that have been identified in the list of skilled skills.

c. The contents of the card: The text of the hearing was selected. The questionnaire was then written in 10 words, and the multiple choices (ten questions) to measure the superficial level of the listening skills followed by a set of questions to be answered. (10 questions) to measure the deep level of listening skills, and the different levels of speech, language, and intellectual speech skills through a card prepared at graduated levels (excellent, very good, good, acceptable, weak). 
The method of measurement is determined by the fact that the students are collected and prepared for the presentation of the story, instructing them, explaining the method of their testing, distribution of the editorial questions and the measuring card, and allowing them - during and after the presentation - to write some vocabulary, Comments, or ideas that help prepare them for the second part of the test for the application of completing the measurement card; they are distributed to three groups of examiners in separate rooms. (3 examiners for each group). The students of the experimental and control groups are tested in one time and randomly distributed to the examiners in the light of their alphabetical order.

E) Control the editorial questions and the measurement card: The test and the card - accompanied by a list of skills - were presented to a group of arbitrators of experts and specialists (10 referees) in teaching Arabic to non-Arabic speakers; to ascertain their sincerity, suitability and necessary correctness.

\section{Experimental Test}

The test was applied to 20 students from the Faculty of Islamic Contemporary Studies, University of Sultan Zainal Abidin, who will not be included in the research experience on 5 September 2016 with the aim of:

a. Ensure the clarity of the test and its instructions.

b. Determine the appropriate time to conduct the test: Display audio story (10 minutes), and to answer questions that measure surface listening skills (thirty minutes after the show for all students), and the right time for each student to answer oral questions in measuring skills card listening and integrated speech (15 minutes per student).

c. Confirmation of the validity of the test; where the survey confirmed the feasibility of the test vocabulary to measure the skills that have been developed to her.

d. Stability of the test: The stability of the test was calculated in the midterm, and the stability coefficient (80\%). This indicates that the test is very stable and applicable.

\section{Proposed Strategy}

The strategy was prepared in light of the following steps:

a. The study of literature and research related to the development of listening and speech skills suitable for Arab learners in general, and related to the identification of the skills of listening and speaking to Arabic learners, especially those who speak Arabic.

b. The researcher benefited from his academic position as a specialist in the curriculum, and methods of teaching Arabic to non-native speakers, and his personal experience in teaching and communicating with them for many years in Egypt, Kazakhstan, Russia, Malaysia, Indonesia and others, as well as consultations with specialists and his fellow teachers in this field.

c. the preparation of a preliminary list of the proposed strategy and presented to a group of arbitrators of experts and specialists (10 arbitrators) in teaching Arabic to non-native 
speakers; to make sure that those who suitability, and its ability to achieve the goals of them, and propose the necessary amendments to them.

d. To make necessary adjustments in the light of the views and proposals of the arbitrators; Preparation of the strategy in its final form. It is in the following stages:

\section{First: Choosing and processing the story on YouTube They include:}

- $\quad$ Selection of the story in the light of linguistic standards, its relevance to the level of students, and their linguistic, psychological and cultural characteristics.

- $\quad$ Extracting the key words and phrases in the story, and starting or translating them into the language of the students.

- $\quad$ Extracting vocabulary and sentences in which linguistic, cultural, or specialized references, or explanation, or representation and metaphor will be made.

- $\quad$ Preparing step-by-step exercises; language and skill on the story in light of the skills list, suitable for the objectives of each stage of the presentation.

\section{Second: Configuration}

\section{They include:}

- $\quad$ Divide students into balanced groups in terms of student level, and choose each group for their own name.

- To alert students to work together in the light of the rules and guidelines of cooperative learning, brainstorming, group discussion, division of roles, and ask questions.

- $\quad$ To warn the students to the need to monitor themselves to the realization of the ear during the listening, focus and distance from distractions, and not preoccupied with the image seen only in understanding the meaning, and not stand long vocabulary or incomprehensible sentences, and try to focus on understanding the general meaning through context and event and image.

- $\quad$ To warn students to the importance of using the dictionary, by writing some words and difficult methods, and then refer to its meaning in the lexicon after the end of the presentation.

- $\quad$ warning students to the division of labor among them in the recording of notes, ideas in terms of vocabulary, language methods, personalities, events, cultural aspects, and subjective feelings.

- $\quad$ Assure them that most of the words in the story are present in their vocabulary, but the problem is in careful listening in a real and original language context.

- Introducing students to the stages of presentation, teaching procedures and discussions, and the tasks required of them at each stage. 
- $\quad$ To warn students that the degree of performance is calculated in light of the overall performance of all members of the group, and the ability to divide the tasks between them to share all the members and interaction.

- Introduce students to the skills of listening and speaking integrated in story learning; to make them targets, seek to acquire and practice during the story.

Third: Presentation and Teaching They include:

a. The first hearing: (surface listening):

- $\quad$ Introduce preliminary questions about the title of the story; to stimulate trends and cultural and social information about the students.

- $\quad$ Teacher's reading of key words and phrases in an audio style that mimics the way they are received in the story.

- $\quad$ The entire first hearing is non-stop, suspended or asked by the professor or students.

- $\quad$ After listening, students are given the opportunity to search the dictionary for the meanings of some vocabulary, and ask quick questions about the meanings and ideas in the story.

- Introduce the initial questions, and address the main characters and events in the story, such as: the identification of some information or attributes or relationships between characters, (personal is ...), and the keys to events (was, went, built,).

- $\quad$ Each group answers the first level surface questions (true and wrong), alerting students to keeping the correct sentence, correcting the wrong sentence, and taking advantage of it to understand and summarize the story's events.

- $\quad$ Evaluate group performance, review exercise solutions, correct errors, and give a score for each group.

b. Second Hearing (in-depth listening):

It includes:

- $\quad$ The chopping of sentences, and the teacher stands at some; randomly chooses one of the group to repeat the audio sentence as it came in text and style in the story and explain the meaning and content, may be asked to use in another context or translated.

- $\quad$ Conduct language, cultural and specialized references, where the teacher to raise students towards some of the words, expressions, images, or events for the work of linguistic, specialized and cultural references. As if referring to an Arabic word that came in the spoken sentence is found in the language of the students, in their specialization or in the Qur'an or in the modern or famous wisdom, or has a cultural relationship related to the Arab, Islamic or global culture or the culture of the students themselves. 
- $\quad$ Language exercises, such as standing on the linguistic roots of some vocabulary, or the question of singular or combination or synonym or counter, or explains the meaning of the method, or explain some of the meanings metaphorical and rhetorical images, or search for the meanings of some words in the lexicon.

- $\quad$ Solving the second level of exercises, and alerts the teacher that the solution of the second level exercises (multiple choices) will help in obtaining a longer story summary that includes partial details about characters and events.

- $\quad$ Evaluate the performance of the groups in the interaction and solve the exercises, giving a score for each group.

\section{c. Third Listening (reinforcing listening):}

\section{And which are:}

- $\quad$ Full listening again without cutting or interventions from the teacher or students.

- $\quad$ Collective work to summarize the story, where each group writes key words and phrases for summary to guide (10) to (15) minutes for each group to summarize the story, review and divide the roles among its members, after which the members of each group will participate in presenting the story summary orally in the order agreed between them.

- $\quad$ Evaluate the performance of groups in interactions, division of roles, summarize story events, and give a score for each group.

Fourth: Consolidation and Evaluation:

They include:

- $\quad$ Conducting the activities and discussions of the calendar, and between the groups by asking questions about the meanings of vocabulary and methods, and formulation in new sentences and attitudes, and character description and governance, and linking the story with personal experiences, and the conclusion of cultural and social characteristics, and ask some questions of discussion and evaluation and cash on the other group, To respond to them, and the teacher intervenes to facilitate the discussions and expand and deepen, and to adjust the sentences and meanings and the consolidation of skills among students.

- $\quad$ Closing the presentation with short and quick sentences from the groups about the story and the linguistic, educational and cultural benefits thereof.

- $\quad$ Evaluate the performance of groups in discussions and responses, and give a score for each group.

Fifth: Extra-curricular activities:

They include:

Each group participates in listening to the story cut, written accurately, translated on video screens, and representing some events. 
Story, video recording for each student in which the story summary, his own impressions, and his cultural calls about them, and what he learned from them, and how he will benefit from it in his life.

- Collective viewing of individual student recordings via the electronic group (Telegram), and collective commentary on each work.

Student through the performance of voice and language, and arrange and complete ideas, and creativity in it, and asked for review and correction and recitation again, taking advantage of the comments and the performance of fellow diligent.

- $\quad$ Publish some students' recordings about the story on their own channel on the Internet.

\section{RESEARCH METHODOLOGY}

The research was based on the descriptive approach in reference to the sources, literature and research related to the research, to root out the research problem, to highlight its aspects and details, to build the research tools and the proposed strategy, and to adopt the experimental approach in selecting the research sample, building the experiment, applying it, data and information collection, analysis and conclusion of the results and formulation of recommendations and proposals.

\section{RESEARCH LIMITS}

\section{Objective Limits:}

Developing listening skills and integrated speech learning, and suitable for sample students.

\section{Time Limits:}

First Semester 2016/2017

\section{Spatial Boundaries:}

Faculty of Islamic Contemporary Studies, University of Sultan Zainal Abidin, Terengganu, Malaysia.

\section{Search society, and his sample:}

The current research experiment was limited to a random sample of Arabic language students in the first semester of the third year of the Faculty of Islamic Contemporary Studies, University of Sultan Zainal Abidin. The sample was divided into two groups, as follows: experimental group (21) students and schoolgirls, and control group (20) students and schoolgirls.

\section{Steps to apply the search experience:}

1. Selecting the narrative content and preparing it to teach the proposed strategy.

2. Selection of the research sample divided into experimental and control.

3. Application of tribal measurement of the experimental and control groups.

4. Teaching to the experimental group with the proposed strategy while examining the control group in the usual way.

5. Apply the post-measurement to the experimental and control groups. 
INTERNATIONAL JOURNAL OF ACADEMIC RESEARCH IN BUSINESS AND SOCIAL SCIENCES Vol. 8, No. 10, Oct. 2018, E-ISSN: 2222-6990 @ 2018 HRMARS

6. Correction of tribal / post-measurement, data collection and analysis and conclusions, recommendations and proposals.

\section{Experimental Design for Search Experience:}

The objective of experimental design to compare (tribal and remote) between the two groups: experimental and control, to find out the effectiveness of the proposed strategy in the development of listening and speaking skills in the experimental group compared to the control group taught using the usual method.

Table no. (1) Shows

Experimental design to conduct the search experiment

\begin{tabular}{|c|c|c|c|}
\hline Group & $\begin{array}{c}\text { Southern } \\
\text { measurement }\end{array}$ & $\begin{array}{c}\text { Experimental } \\
\text { Variable }\end{array}$ & $\begin{array}{c}\text { Dimensional } \\
\text { measurement }\end{array}$ \\
\hline $\begin{array}{c}\text { Control and } \\
\text { supervision }\end{array}$ & $\begin{array}{c}\text { Southern } \\
\text { application of the } \\
\text { measurement tool }\end{array}$ & $\begin{array}{c}\text { Teaching in the } \\
\text { usual way }\end{array}$ & $\begin{array}{c}\text { Dimensional } \\
\text { application of the } \\
\text { measurement tool }\end{array}$ \\
\hline Experimental & $\begin{array}{c}\text { Southern } \\
\text { application of the } \\
\text { measurement tool }\end{array}$ & $\begin{array}{c}\text { Teaching by using } \\
\text { the proposed } \\
\text { strategy }\end{array}$ & $\begin{array}{c}\text { Dimensional } \\
\text { application of the } \\
\text { measurement tool }\end{array}$ \\
\hline
\end{tabular}

Whereas, S1 = Southern application of the measurement tool, S2 = Dimensional application of the measurement tool

\section{Southern measurement procedure:}

It has been proceeded the southern measurement performed on two groups: experimental and control, in order to determine the performance of the two groups level in the measurement of listening and integrated speech skills test, and stand over the extent to which they are equal before teaching using the strategy proposed experimental group, teaching in the usual way for the control group, were used to test the " $T$ " equation to calculate the Statistical differences between the mean scores of the two groups.

The following table shows the arithmetic mean, the standard deviation, the value of $T$ and its significance to the average scores of the experimental and control groups in the Southern measurement of students' skills. 
INTERNATIONAL JOURNAL OF ACADEMIC RESEARCH IN BUSINESS AND SOCIAL SCIENCES Vol. 8, No. 10, Oct. 2018, E-ISSN: 2222-6990 ㄷ 2018 HRMARS

Table (2) shows

Arithmetic mean of the standard deviation and the value of the $t$ for the 2 averages of marks of Control and Experimental groups and their significance in southern measurement of integrated listening and speech skills

\begin{tabular}{|c|c|c|c|c|c|c|c|}
\hline Group & Number & $\begin{array}{c}\text { Arithmetic } \\
\text { average }\end{array}$ & $\begin{array}{c}\text { standard } \\
\text { deviation }\end{array}$ & $\begin{array}{c}\text { Difference } \\
\text { between } \\
\text { the two } \\
\text { averages }\end{array}$ & $\begin{array}{c}\text { T } \\
\text { calculated }\end{array}$ & $\begin{array}{c}\text { T } \\
\text { Tabulated }\end{array}$ & Significance \\
\hline $\begin{array}{c}\text { Control and } \\
\text { supervision }\end{array}$ & 20 & 6.433 & $3.47^{`} 61$ & & 0.71 & 2.63 & $\begin{array}{c}\text { Not } \\
\text { statistically } \\
\text { significant }\end{array}$ \\
\hline
\end{tabular}

It is clear from the previous table that there is no statistically significant difference at any level of significance between the two groups: control and experimentation, indicating that the two groups are equal in the southern measurement; the difference between the averages is 0.112 , the table value is 2.63 and the calculated value is 0.71 . The percentage of performance of the two groups in the test was calculated as $11.8 \%$ for the control group and $12.3 \%$ for the experimental group, indicating the weakness of the two groups in listening and speaking skills and the need to look for strategies and development programs.

\section{Teaching selected stories:}

- The experimental group: studied using the proposed strategy, through the use of the manual prepared for this purpose.

- Control group: I studied the same stories using the usual method?

- The researcher was keen to have both teachers in the experimental group, and the control group on the same level of experience and degree.

- The application of the research experience lasted three months from 8/9/2016 until $812 / 2016$, with an average of two hours of teaching per week. Six students were studied at a rate of four hours per story and the researcher continued to follow up on the teachers' difficulties and problems.

- The dimensional-measurement was conducted on $11 / 12 / 2016$ by applying the test of measuring listening and speaking skills to the students of the two groups at the same time in the same way as the southern measurement.

\section{RESEARCH RESULTS}

\section{First: To answer the question}

What is the effectiveness of the proposed strategy in developing the overall listening and speaking skills of the experimental group as compared to the students of the control group studied in the usual way? 
INTERNATIONAL JOURNAL OF ACADEMIC RESEARCH IN BUSINESS AND SOCIAL SCIENCES

Vol. 8, No. 10, Oct. 2018, E-ISSN: 2222-6990 ㄷ 2018 HRMARS

The researcher analyzed the results of the students in the two groups in the post-application using the statistical program (SPSS) and calculation of the arithmetical mean and standard deviation and the value of its significance to the average scores of the two groups was as shown in the following table:

Table (3) shows

Arithmetic mean of the standard deviation and the value of the $t$ for the 2 averages of marks of Control and Experimental groups and their significance in southern measurement For measurement as a whole.

\begin{tabular}{|c|c|c|c|c|c|c|c|}
\hline Group & Number & $\begin{array}{c}\text { Arithmetic } \\
\text { average }\end{array}$ & $\begin{array}{c}\text { standard } \\
\text { deviation }\end{array}$ & $\begin{array}{c}\text { Difference } \\
\text { between } \\
\text { the two } \\
\text { averages }\end{array}$ & $\begin{array}{c}\text { T } \\
\text { calculated }\end{array}$ & Tabulated & Significance \\
\hline $\begin{array}{c}\text { Control and } \\
\text { supervision }\end{array}$ & 20 & 19.742 & 7.886 & \multirow{2}{*}{12.115} & 5.905 & 2.63 & $\begin{array}{c}\text { Statistical } \\
\text { function at } \\
0.01\end{array}$ \\
\hline Experimental & 21 & 31.857 & 8.294 & &
\end{tabular}

It is clear from the previous table that the value of " $T$ " calculated for the difference between the mean scores of the two groups: the experimental and the control in the distance measurement of the listening and integrated speech skills (5.905) are greater than the table value of (2.63) the following research:

There is a statistically significant difference between the mean scores of the two groups: experimental and control in the post-test application as a whole for the benefit of the experimental group, as shown in the following diagram.

A diagram shows The arithmetic average of the students' grades: experimental and control in the dimensional-application In Table 3, the graph shows the difference between the average scores of the two groups: experimental and control, in the dimensional application in favor of the experimental group, with a difference of 12,115 . The researcher assigns the progress made by the students in the experimental group to the proposed strategic teacher This strategy has achieved important objectives, including: attracting students' attention, learning fun, participating actively in interactive discussions and activities, and building effective self-learning strategies that enabled them to acquire vocabulary, understand and form sentences, And helped them to understand the elements of the story and its contents in depth, and follow up events and personalities accurately, and thus helped them to express ideas and feelings around them, and start to speak expression, conclusion, summary, discussion and criticism. 
INTERNATIONAL JOURNAL OF ACADEMIC RESEARCH IN BUSINESS AND SOCIAL SCIENCES Vol. 8, No. 10, Oct. 2018, E-ISSN: 2222-6990 ㄷ 2018 HRMARS

The strategy also highlights the role of integration in the development of listening and speaking skills among students. The growth of listening skills among students has positively influenced the development of speech skills.

- Receive skills in listening to production skills that facilitate students' easy speech. As well as the researcher.

The experimental group excels in the interest of the strategy by expressing students' feelings about the story, linking it to their personal experiences, and cultural characteristics in Arab, Islamic and global culture.

The results of the current research are consistent with the results of some Arab research that sought to build strategies and teaching programs for development of the skills of listening only or speech only or both together with non-Arabic speaking students, such as Taaima, (2004), (Hassan, 2005), (Jalal, 2009), \& (al-Anati, 2009), (Hidayat, 2009), (Rahman, 2013), (Boungma (2013) and (Salem, \& Hassan, 2016).

\section{Research Recommendations}

In light of the above results, the research recommends:

1. Use of the proposed strategy in the development of listening and speaking skills among learners of the Arabic language speakers in other different levels of education.

2. Attention to the integration of the four language skills in general, and the skills of listening and speaking in particular in the curricula and methods of teaching to Arabic-speaking learners.

3. Interest in stories - especially stories seen on social networking sites - and use in development Language skills, and cultural knowledge among Arab-speaking learners, provided they are selected and processed in light appropriate procedures and standards.

4. Training Arabic teachers to non-speakers on the latest strategies in the development of language skills, as well as training on taking advantage of the original language materials on the web.

5. Interest in the interaction of students with the original materials in the teaching of Arabic to non-speakers, because it represents the real language that students must acquire and interact with them in the future.

6. Interest in the teaching of students who speak non - Arabic methods of effective teaching based on language practice, participation, cooperation, interaction, and collective discussion, brainstorming, and express emotions and ideas of cash and creativity.

\section{Research Suggestions (Proposals)}

In the light of the above results, the research offers the following proposals: 
INTERNATIONAL JOURNAL OF ACADEMIC RESEARCH IN BUSINESS AND SOCIAL SCIENCES Vol. 8, No. 10, Oct. 2018, E-ISSN: 2222-6990 @ 2018 HRMARS

1. Research on the building of effective strategies and programs based on the entrances and theories of modern development of language skills among Arabic-speaking learners at different levels.

2. Research the impact of integration between the four language skills in the acquisition of students who speak non - Arabic.

3. Research on the selection criteria and processing of the original language materials in Arabic on the Internet; for use in teaching Arabic to non-Arabic speakers.

4. Research in the integrated language skills that can be developed through the audio, viewing or reading materials in the programs of teaching Arabic to other speakers.

5. Research the effectiveness of stories in the development of different language skills among Arabic-speaking learners.

\section{ACKNOWLEDGEMENT}

Special appreciations to the Research Management, Innovation \& Commercialization (RMIC), Universiti Sultan Zainal Abidin (UniSZA) \& the Faculty of Islamic Contemporary Studies (FKI, UniSZA) for sponsoring the project.

\section{REFERENCES}

Saleh, A.Z. (1996). Educational Psychology. Egypt: Nahdet Misr Library.

Ghazaleh, A. \& Sulaiman, W. ( 2002). Effect of therapeutic program on improving the listening skills of the ninth grade students in the schools of the Directorate of Education in Jerash Governorate. Unpublished Master Thesis, Yarmouk University.

Bakr, B.A. \& Hachem, I. (1984). Teaching expression for speakers in other languages. Journal of the Institute of Arabic Language.

Shehata, H. (1996). Teaching Arabic Language between Theory and Practice. Cairo: The Egyptian Lebanese House.

Taaima, R. (1986). Reference in Teaching Arabic to Speakers of Other Languages. Saudi Arabia: Umm Al Qura University.

Taaima, R. (2004). Language skills, levels, teaching, difficulties. Cairo: Dar Al-Fikr al-Arabi.

Salem, S. (2015). Methods of developing the skill of conversation to the higher levels (excellence, excellence). Working paper presented in the First International Conference, The Teaching of Arabic to Non-Speakers, Visions And Experiences. Istanbul Foundation for Education and Research (Ithar), Turkey, 25-26 April.

Madkour, A. (1991). Teaching Arabic Language Arts. Cairo: Dar al-Shawaf.

Ibrahim, A. (1966). Instructor of Arabic Language Teaching. Egypt: Dar al-Ma'aref,

Hatab. F.A. \& Sadek, A. (1996). Educational Psychology. Cairo: Anglo-Egyptian.

Younis, F. \& Raouf S.M.A. (2003). The Reference in the Teaching of the Arabic Language for Foreigners, from Theory to Application. Cairo: Wahba Library.

Boungma, M. (2013). Teaching Arabic to speakers of other languages, teaching methodology between theory and practice. Paper work in Second International Conference on

Al-Khatib. A. (2008). Arabic Language Curriculum and Methods of Teaching in Basic Education. Amman: al-Rawwaq Publishing \& Distribution. 
INTERNATIONAL JOURNAL OF ACADEMIC RESEARCH IN BUSINESS AND SOCIAL SCIENCES

Vol. 8, No. 10, Oct. 2018, E-ISSN: 2222-6990 ㄷ 2018 HRMARS

Khater. M.R. (1989). Methods of teaching Arabic language and religious education in the light of modern educational trends. Egypt: Dar al-Ma`arif.

Al-Naqa, M. \& Hafez. (2002). Teaching Arabic in General Education, its Entries and Techniques . Cairo: Alekhlas Library.

El-Laboudi. M. (2003). Dialogue: His Art, Strategies and Methods of Learning. Cairo: Wahba Library. Abdulhadi. N. (2003). Language and Thinking Skills, Dar Al-Masirah Publishing and Distribution, Amman.

Al-Mursi. W. \& Khalaf, A.H.M. (2010). Modern Trends in Teaching Arabic Language. Saudi Arabia: alNadi al-Adabi.

Al-Anati. W. (2009). A Linguistic Vision in Teaching Short Stories to Non-Arab Speakers. Humanities. 23(1): 73-94.

Jabr. Y. (1992). Reading of the Hearing: Journal of Education. 102(1): 113-128.

Brown, H. (2010). Principles of Language Learning and Teaching. New Jersey: Prentice, Hall, Inc. 